\title{
Declining complication rates with flow diversion of anterior circulation aneurysms after introduction of the Pipeline Flex: analysis of a single-institution series of 568 cases
}

\author{
*Geoffrey P. Colby, MD, PhD, ${ }^{1}$ Matthew T. Bender, MD, ${ }^{1}$ Li-Mei Lin, MD, ${ }^{2}$ Narlin Beaty, MD, ${ }^{1}$ \\ Justin M. Caplan, MD, ${ }^{1}$ Bowen Jiang, MD, ${ }^{1}$ Erick M. Westbroek, MD, ${ }^{1}$ Bijan Varjavand, MD, ${ }^{1}$ \\ Jessica K. Campos, MD, ${ }^{1}$ Judy Huang, MD, ${ }^{1}$ Rafael J. Tamargo, MD, ${ }^{1}$ and Alexander L. Coon, MD${ }^{1}$ \\ 1Department of Neurosurgery, Johns Hopkins Medicine, Baltimore, Maryland; and 2Department of Neurosurgery, University of \\ California Irvine, Orange, California
}

\begin{abstract}
OBJECTIVE The second-generation Pipeline embolization device (PED), Flex, has several design upgrades, including improved opening and the ability to be resheathed, in comparison with the original device (PED classic). The authors hypothesized that Flex is associated with a lower rate of major complications.

METHODS A prospective, IRB-approved, single-institution database was analyzed for all patients with anterior circulation aneurysms treated by flow diversion. The PED classic was used from August 2011 to January 2015, and the Pipeline Flex has been used since February 2015.

RESULTS A total of 568 PED procedures (252 classic and 316 Flex) were performed for anterior circulation aneurysms. The average aneurysm size was $6.8 \mathrm{~mm}$. Patients undergoing treatment with the Flex device had smaller aneurysms $(p$ $=0.006$ ) and were more likely to have undergone previous treatments $(p=0.001)$. Most aneurysms originated along the internal carotid artery ( $89 \%$ classic and $75 \%$ Flex) but there were more anterior cerebral artery $(18 \%)$ and middle cerebral artery $(7 \%)$ deployments with Flex $(p=0.001)$. Procedural success was achieved in $96 \%$ of classic and $98 \%$ of Flex cases $(p=0.078)$. Major morbidity or death occurred in $3.5 \%$ of cases overall: $5.6 \%$ of classic cases, and $1.9 \%$ of Flex cases $(p=0.019)$. On multivariate logistic regression, predictors of major complications were in situ thrombosis $(O R 4.3$, $p=0.006)$, classic as opposed to Flex device $(\mathrm{OR} 3.7, p=0.008)$, and device deployment in the anterior cerebral artery or middle cerebral artery as opposed to the internal carotid artery (OR $3.5, p=0.034)$.
\end{abstract}

CONCLUSIONS Flow diversion of anterior circulation cerebral aneurysms is associated with an overall low rate of major complications. The complication rate is significantly lower since the introduction of the second-generation PED (Flex).

https://thejns.org/doi/abs/10.3171/2017.7.JNS171289

KEY WORDS cerebral aneurysm; Pipeline embolization; flow diversion; vascular disorders

$\mathrm{S}$ INCE its approval in Europe in 2009 and the United States in 2011, the Pipeline embolization device (PED; Medtronic) has been a breakthrough technology for the treatment of large, proximal carotid artery aneurysms as well as a broad range of small, ${ }^{6,18}$ distal anterior circulation ${ }^{7}$ and posterior circulation aneurysms. ${ }^{15}$ The second-generation device, the Pipeline Flex, received
US FDA approval in 2015. This device has the same stent technology as the Pipeline classic, but the delivery system has been overhauled, allowing for resheathing, enhanced opening, and improved navigability. ${ }^{8,20}$ Reduced procedural time and radiation exposure have been demonstrated with the PED Flex. ${ }^{16}$ We hypothesized that the enhanced delivery system of PED Flex has also resulted in a signifi-

ABBREVIATIONS ACA = anterior cerebral artery; Cat5 = AXS Catalyst 5; ICA = internal carotid artery; ICH = intracranial hemorrhage; IntrePED = International Retrospective Study of the Pipeline Embolization Device; MCA = middle cerebral artery; PED = Pipeline embolization device; PRU = P2Y12 reaction units; PUFS = Pipeline for Uncoilable or Failed Aneurysms; SAH = subarachnoid hemorrhage; TIA = transient ischemic attack.

SUBMITTED May 25, 2017. ACCEPTED July 24, 2017.

INCLUDE WHEN CITING Published online January 12, 2018; DOI: 10.3171/2017.7.JNS171289.

* Drs. Colby and Bender share first authorship of this work. 
cant reduction in clinical adverse events. This is a retrospective series of all 568 anterior circulation aneurysms that were treated with Pipeline devices at Johns Hopkins Medicine from 2011 to 2016 to assess procedural outcomes, complications, and predictors thereof.

\section{Methods}

This was a retrospective cohort study from an institutional review board-approved, prospectively collected database of patients with aneurysms that were treated at a tertiary medical center. All patients who underwent PED placement for anterior circulation aneurysms between $\mathrm{Au}-$ gust 2011 and December 2016 were included in this study. Patient consent was not required, as data are collected in a de-identified manner on routine clinical practice at our institution. Patients were started on a regimen of dual antiplatelet therapy 7 days before their procedure. Assessment of P2Y12 response (VerifyNow, Accumetrics) was performed on a case-by-case basis, with increased frequency after January 1, 2014, although still representing a minority of patients. Clinical signs of hyperresponse (e.g., significant extremity bruising, bleeding gums, spontaneous epistaxis) occasionally led to medication dose adjustment and procedural rescheduling, with or without a confirmatory low P2Y12 value. No action was taken for patients with elevated P2Y12 reaction units (PRU; > 200). The first-generation PED (PED classic) was used from August 2011 through January 2015, and the PED Flex was used in all subsequent cases. PED placement was performed as previously described ${ }^{8,9}$ through an 8 -Fr femoral sheath and a triaxial system that consisted of a long guide sheath, distal access catheter, and 0.027-inch microcatheter. The guide sheaths included the Flexor Shuttle guiding sheath (0.087-inch inner diameter; Cook Medical), Neuron MAX (0.088-inch inner diameter; Penumbra), and AXS Infinity (0.088-inch inner diameter; Stryker Neurovascular). The distal intracranial catheter included the Navien (0.058inch inner diameter; Medtronic), AXS Catalyst 5 (Cat5; Stryker Neurovascular), and an intermediate catheter (0.060-inch inner diameter; InNeuroCo). The microcatheters used included the Marksman (Medtronic) and Via27 (Sequent Medical/MicroVention Terumo Corp.). Patients recovered in the neurocritical care unit and were typically discharged home on postprocedure day 1. Demographic information, clinical history, and outcomes were collected from medical records. Anatomical and technical details were collected from angiograms and operative reports through March 2017. Major stroke was defined as a change in the National Institutes of Health Stroke Scale score of greater than 4 lasting more than 7 days; minor stroke was a change in score of 4 or lower lasting fewer than 7 days with corroborative imaging; and transient ischemic attack (TIA) was a transient neurological deficit without corroborative imaging.

\section{Statistical Analysis}

Data are presented as means with SD and ranges for continuous variables and as frequency for categorical variables. Univariate analysis was carried out using unpaired t-tests and ANOVA tests. Bivariate logistic regression was used to test covariates predictive of major complications along with device type. Factors predictive at a level of $\mathrm{p}$ $<0.2$ were then evaluated by multivariate logistic regression. A threshold of $\mathrm{p}<0.05$ was used to determine significance. Statistical analysis was performed using Stata (version 14.0, StataCorp).

\section{Results}

A total of 568 procedures were performed in 494 patients (252 classic and 316 Flex cases). Overall, the average patient age was 56.3 years, and patients in $82 \%$ of the cases were female. The average aneurysm size was 6.8 $\mathrm{mm}$, and $79 \%$ of aneurysms were smaller than $10 \mathrm{~mm}$. A minority of patients had prior subarachnoid hemorrhage (SAH; $15 \%$ ), and a minority of aneurysms had been previously treated (18\%). Patients treated with PED Flex were younger $(p=0.004)$, had smaller aneurysms $(p=0.006)$, and were more likely to have undergone previous treatment, most commonly coiling $(\mathrm{p}=0.001)$. Patients undergoing PED classic were more likely to have cervical internal carotid artery (ICA) tortuosity $(\mathrm{p}<0.001)$, but the 2 groups had similar aortic and cavernous ICA anatomy (Table 1).

With both PED classic and Flex, a majority of treated aneurysms (89\% and $75 \%$, respectively) originated from the ICA; however, there was an increasing percentage of anterior cerebral artery (ACA; 18\%) and middle cerebral artery (MCA; 7\%) aneurysms that were treated with PED Flex $(\mathrm{p}=0.001)$ (Table 2).

Procedural success was achieved in a greater percentage of PED Flex (98\%) than PED classic (96\%) cases, although this was not statistically significant $(\mathrm{p}=0.078)$. PED Flex procedures required less fluoroscopy time ( $p<$ $0.001)$ and radiation exposure $(\mathrm{p}<0.001)$, despite the fact that more devices were used on average $(\mathrm{p}=0.006)$. There was a reduction in device removal with PED Flex $(\mathrm{p}<$ 0.001). Prophylactic intraarterial verapamil was used more commonly with Pipeline Flex, as these devices were deployed in a more distal circulation $(\mathrm{p}<0.001)$. A trend toward more adjunctive coiling with Flex (9\%) as compared with classic $(6 \%)$ did not reach statistical significance $(\mathrm{p}$ $=0.105)$. There were similar rates of balloon angioplasty (13\%) and stent thrombosis (4\%), and 1 instance of wire perforation $(0.4 \%)$ with each device generation (Table 3 ).

The overall average length of stay was 2.3 days, and $94 \%$ of patients were discharged to home or to their prior level of care (Table 4). The mean follow-up was 11.6 months with a median of 9.4 months. The overall rate of major complications (encompassing major stroke, intracranial hemorrhage [ICH], SAH, and mortality) was $3.5 \%$ and was lower for PED Flex (1.9\%) than for PED classic $(5.6 \%)(p=0.019)$. For PED classic, the rates of major stroke, ICH, SAH, and mortality were $2.0 \%, 2.4 \%, 1.2 \%$, and $1.6 \%$, respectively. For PED Flex, the rates were $0.3 \%$, $1.3 \%, 0.3 \%$, and $0.6 \%$, respectively. There were no statistically significant differences by device generation for any of these major complication subtypes when considered individually. Minor complications (encompassing TIA, minor stroke, exacerbation of cranial nerve palsy, iatrogenic dissection without neurological deficit, groin hematoma, 
TABLE 1. Demographics and anatomy

\begin{tabular}{|c|c|c|c|c|}
\hline \multirow[b]{2}{*}{ Variable } & \multicolumn{3}{|c|}{ Value } & \multirow{2}{*}{$\begin{array}{c}p \\
\text { Value }\end{array}$} \\
\hline & Classic & Flex & Total & \\
\hline Total no. of cases & 252 & 316 & 568 & \\
\hline Age in yrs & & & & 0.004 \\
\hline Mean \pm SD & $54.6 \pm 13.2$ & $57.7 \pm 12.3$ & $56.3 \pm 12.8$ & \\
\hline Range & $20-88$ & $21-86$ & $20-88$ & \\
\hline Female sex & $210(83.3)$ & $258(81.6)$ & $468(82.4)$ & 0.601 \\
\hline Size in $\mathrm{mm}$ & & & & 0.006 \\
\hline Mean \pm SD & $7.4 \pm 5.0$ & $6.3 \pm 5.2$ & $6.8 \pm 5.2$ & \\
\hline Range & $1-25$ & $1-37$ & $1-37$ & \\
\hline Small & $185(73.4)$ & $265(83.9)$ & $450(79.2)$ & 0.002 \\
\hline Large & $66(26.2)$ & $46(14.6)$ & $112(19.7)$ & \\
\hline Giant & $1(0.4)$ & $5(1.6)$ & $6(1.1)$ & \\
\hline Prior SAH & 28 (11.1) & $55(17.4)$ & $83(14.6)$ & 0.082 \\
\hline Previous treatment & $31(12.3)$ & $71(22.5)$ & $102(18.0)$ & 0.001 \\
\hline Clip & $11(4.4)$ & $13(4.1)$ & $24(4.2)$ & \\
\hline Coil & $18(7.1)$ & $48(15.2)$ & $66(11.6)$ & \\
\hline Flow diversion & $2(0.8)$ & $10(3.2)$ & $12(2.1)$ & \\
\hline $\begin{array}{l}\text { Significant cervical } \\
\text { ICA tortuosity }\end{array}$ & $113(44.8)$ & $85(26.9)$ & 198 (34.9) & 0.000 \\
\hline Cavernous ICA type* & & & & 0.062 \\
\hline la & $42(16.7)$ & $64(20.3)$ & $106(18.7)$ & \\
\hline $\mathrm{lb}$ & $72(28.6)$ & $98(31.0)$ & $170(29.9)$ & \\
\hline II & $44(17.5)$ & $62(19.6)$ & $106(18.7)$ & \\
\hline III & $63(25.0)$ & $65(20.6)$ & $128(22.5)$ & \\
\hline IV & $29(11.5)$ & $27(8.5)$ & $56(9.9)$ & \\
\hline NA & $2(0.8)$ & $0(0.0)$ & $2(0.4)$ & \\
\hline Aortic arch type $†$ & & & & 0.851 \\
\hline 1 & $45(17.9)$ & $27(8.5)$ & $72(12.7)$ & \\
\hline 2 & $71(28.2)$ & $41(13.0)$ & $112(19.7)$ & \\
\hline 3 & $17(6.7)$ & $8(2.5)$ & $25(4.4)$ & \\
\hline NA & $119(47.2)$ & $240(75.9)$ & 359 (63.2) & \\
\hline
\end{tabular}

$\mathrm{NA}=$ not available

Values are presented as the number of aneurysms (\%) unless stated otherwise. * Type I, mild tortuosity; types II and III, moderate tortuosity; and type IV, severe tortuosity. For more information, refer to Lin LM, Colby GP, Jiang B, et al: Classification of cavernous internal carotid artery tortuosity: a predictor of procedural complexity in Pipeline embolization. J Neurointerv Surg 7:628-633, 2015.

$\dagger$ Type 1, great vessels originate at the same level as the upper convexity; type 2 , great vessels originate between the upper and lower convexities; and type 3 , great vessels originate below the lower convexity.

and groin infection) were similar for the 2 generations of Pipeline device $(\mathrm{p}=0.083)$.

Multivariate logistic regression was performed to identify predictors of major complications. Predictors of major complication were in situ thrombosis (OR 4.3, $\mathrm{p}=0.006)$, PED classic as opposed to Flex device (OR 3.7, $\mathrm{p}=0.008$ ), and device deployment in the ACA or MCA as opposed to the ICA (OR 3.5, $\mathrm{p}=0.034$ ) (Table 5). Notable variables that were not predictive of major complication included aneurysm size, morphology, prior treatment, adjunctive coiling, balloon angioplasty, catheter technology, and ana-
TABLE 2. Aneurysm location

\begin{tabular}{|c|c|c|c|}
\hline \multirow[b]{2}{*}{ Location } & \multicolumn{3}{|c|}{ No. of Aneurysms } \\
\hline & Classic & Flex & Total \\
\hline ICA & $228(89.1)$ & $238(75.3)$ & $466(82.0)$ \\
\hline Cervical & $8(3.1)$ & $6(1.9)$ & $14(2.5)$ \\
\hline Petrous & $2(0.8)$ & $2(0.6)$ & $4(0.7)$ \\
\hline Cavernous & $38(14.8)$ & $30(9.5)$ & $68(12.0)$ \\
\hline Ophthalmic & $50(19.5)$ & $47(14.9)$ & $97(17.1)$ \\
\hline Paraophthalmic & $94(36.7)$ & $66(20.9)$ & $160(28.2)$ \\
\hline Superior hypophyseal & $4(1.6)$ & $6(1.9)$ & $10(1.8)$ \\
\hline Posterior communicating & $13(5.1)$ & 48 (15.2) & $61(10.7)$ \\
\hline Anterior choroidal & $0(0.0)$ & $2(0.6)$ & $2(0.4)$ \\
\hline Clinoidal & $9(3.5)$ & $12(3.8)$ & $21(3.7)$ \\
\hline Supraclinoid & $8(3.1)$ & $12(3.8)$ & $20(3.5)$ \\
\hline Termination & $2(0.8)$ & $7(2.2)$ & $9(1.6)$ \\
\hline ACA & $23(9.0)$ & $56(17.7)$ & $79(13.9)$ \\
\hline$A_{1}$ & $3(1.2)$ & $4(1.3)$ & $7(1.2)$ \\
\hline$A_{1} / A_{2}$ & $9(3.5)$ & $12(3.8)$ & $21(3.7)$ \\
\hline Anterior communicating & $9(3.5)$ & $32(10.1)$ & $41(7.2)$ \\
\hline $\mathrm{A}_{2} / \mathrm{A}_{3}$ & $2(0.8)$ & $7(2.2)$ & $9(1.6)$ \\
\hline $\mathrm{A}_{4}$ & $0(0.0)$ & $1(0.3)$ & $1(0.2)$ \\
\hline MCA & $5(2.0)$ & $22(7.0)$ & $27(4.8)$ \\
\hline$M_{1}$ & $2(0.8)$ & $6(1.9)$ & $8(1.4)$ \\
\hline Bifurcation & $2(0.8)$ & $12(3.8)$ & $14(2.5)$ \\
\hline $\mathrm{M}_{2}$ & $1(0.4)$ & $3(0.9)$ & $4(0.7)$ \\
\hline Distal & $0(0.0)$ & $1(0.3)$ & $1(0.2)$ \\
\hline
\end{tabular}

tomical features, including cervical tortuosity and highgrade cavernous anatomy.

\section{Discussion}

In this series of 494 patients who underwent 568 Pipeline procedures (252 PED classic and 316 PED Flex) for anterior circulation cerebral aneurysms over a 5-year period (2011-2016), there was a high rate of procedural success $(97 \%)$ and low overall rate of major complications (3.5\%), including major stroke, $\mathrm{SAH}, \mathrm{ICH}$, and mortality. Compared with the PED classic, Flex was associated with a higher rate of procedural success, less radiation, and a reduced rate of major complications $(<2 \%)$, which persisted on multivariate logistic regression after accounting for procedural and patient differences.

The types of aneurysms being treated with PEDs have changed since their introduction; initial success with large proximal carotid artery aneurysms gave way to treatment of small carotid artery aneurysms and finally to more distal anterior circulation aneurysms. This 5-year study incorporates all of these time points, and the outcomes compare favorably with those of published studies that include aneurysms of each type.

Early prospective studies of PEDs showed higher complication rates in a population of larger aneurysms. The major complication rate in the Pipeline for Uncoilable or Failed Aneurysms (PUFS) trial was 5.6\%, with a mortality 
TABLE 3. Procedural outcomes

\begin{tabular}{|c|c|c|c|c|}
\hline \multirow[b]{2}{*}{ Outcome } & \multicolumn{3}{|c|}{ Value } & \multirow{2}{*}{$\begin{array}{c}p \\
\text { Value }\end{array}$} \\
\hline & Classic & Flex & Total & \\
\hline $\begin{array}{l}\text { Procedural suc- } \\
\text { cess }\end{array}$ & $242(96.0)$ & $311(98.4)$ & $553(97.4)$ & 0.078 \\
\hline $\begin{array}{l}\text { Total fluoroscopy } \\
\text { time in mins }\end{array}$ & & & & $<0.001$ \\
\hline Mean \pm SD & $43.4 \pm 21.3$ & $35.3 \pm 21.7$ & $39.1 \pm 24.7$ & \\
\hline Range & $14.1-202.7$ & $10.0-151.7$ & $10.0-202.7$ & \\
\hline $\begin{array}{c}\text { Radiation expo- } \\
\text { sure in mGy }\end{array}$ & & & & $<0.001$ \\
\hline Mean \pm SD & $2446 \pm 1308$ & $2033 \pm 1072$ & $2224 \pm 1196$ & \\
\hline Range & $178-9134$ & $259-7014$ & $178-9134$ & \\
\hline No. of PEDs & & & & 0.006 \\
\hline Mean \pm SD & $1.07 \pm 0.25$ & $1.14 \pm 0.34$ & $1.11 \pm 0.39$ & \\
\hline Range & $1-2$ & $1-3$ & $1-3$ & \\
\hline $\begin{array}{l}\text { Adjunct coil } \\
\text { deployment }\end{array}$ & $14(5.6)$ & $29(9.2)$ & $43(7.6)$ & 0.105 \\
\hline $\begin{array}{l}\text { Spasm (vera- } \\
\text { pamil) }\end{array}$ & $11(4.4)$ & $53(16.8)$ & $64(11.3)$ & $<0.001$ \\
\hline $\begin{array}{l}\text { Balloon angio- } \\
\text { plasty }\end{array}$ & $25(9.9)$ & $47(14.9)$ & 72 (12.7) & 0.107 \\
\hline PED thrombosis & $6(2.4)$ & $17(5.4)$ & $23(4.0)$ & 0.085 \\
\hline Wire perforation & $1(0.4)$ & $1(0.3)$ & $2(0.4)$ & 0.378 \\
\hline $\begin{array}{l}\text { PED cork/re- } \\
\text { moval }\end{array}$ & 38 (15.1) & $8(2.5)$ & $46(8.1)$ & 0.001 \\
\hline
\end{tabular}

Values are presented as the number of aneurysms (\%) unless stated otherwise.

rate of $1.9 \%$, but the mean aneurysm size was $18 \mathrm{~mm}$, and $20 \%$ of aneurysms were $\geq 25 \mathrm{~mm} .{ }^{1}$ Similarly, the ASPIRe (Aneurysm Study of Pipeline in an Observational Registry) reported major morbidity of $6.8 \%$ and mortality of $1.6 \%$ among 191 on-label PED treatments for aneurysms with an average size of $14.5 \mathrm{~mm} \cdot{ }^{14}$ By comparison, the major complication rate in this study was $3.5 \%$ with a mortality rate of $1.1 \%$. The paucity of giant aneurysms (1\%) in the present study may limit direct comparisons to these early series, but within a population of small and large aneurysms, it is noteworthy that size was not a predictor of major complications. This corroborates the findings of the International Retrospective Study of the Pipeline Embolization Device (IntrePED), in which neurological morbidity and mortality was comparable for small (5\%) and large $(9 \%)$ anterior circulation aneurysms but was much higher for giant aneurysms $(23 \%){ }^{15}$

The rate of major complications in this series also compares favorably to that of other series reporting on PEDs for small, predominantly ICA aneurysms. Among 294 patients included in IntrePED with anterior circulation aneurysms smaller than $10 \mathrm{~mm}$, the reported rates of ICH $(2.0 \%)$, stroke $(2.7 \%)$, major morbidity $(4.5 \%)$, and neurological mortality (1.4\%) were all higher than rates of similar complications observed in the current series. ${ }^{15}$ Likewise, in a prospective series of 143 patients from Hong Kong with an average aneurysm size of $7 \mathrm{~mm}$ and 97\% anterior circulation aneurysms, the major complication
TABLE 4. Clinical outcomes

\begin{tabular}{lccrc}
\hline \multirow{2}{*}{ Outcome } & \multicolumn{3}{c}{ Value } & $\begin{array}{c}\text { p } \\
\text { Value }\end{array}$ \\
\cline { 2 - 4 } & Classic & Flex & Total & 0.085 \\
\hline LOS in days & & & & \\
\hline \multicolumn{1}{c}{ Mean \pm SD } & $2.60 \pm 4.8$ & $2.01 \pm 3.3$ & $2.27 \pm 4.1$ & \\
\hline Range & $1-48$ & $1-30$ & $1-48$ & \\
\hline Discharge POD 1 & $158(62.7)$ & $235(74.4)$ & $393(69.2)$ & 0.003 \\
\hline Discharge home/prior & $236(93.7)$ & $300(94.9)$ & $536(94.4)$ & 0.509 \\
$\quad$ level of care & & & & \\
\hline Major complication & $14(5.6)$ & $6(1.9)$ & $20(3.5)$ & 0.019 \\
\hline Minor complication & $28(11.1)$ & $22(7.0)$ & $50(8.8)$ & 0.083 \\
\hline Mortality & $4(1.6)$ & $2(0.6)$ & $6(1.1)$ & 0.270 \\
\hline Minor stroke & $2(0.8)$ & $3(0.9)$ & $5(0.9)$ & 0.820 \\
\hline Major stroke & $5(2.0)$ & $1(0.3)$ & $6(1.1)$ & 0.054 \\
\hline ICH & $6(2.4)$ & $4(1.3)$ & $10(1.8)$ & 0.316 \\
\hline SAH & $3(1.2)$ & $1(0.3)$ & $4(0.7)$ & 0.217 \\
\hline Transient deficit & $3(1.2)$ & $10(3.2)$ & $13(2.3)$ & 0.119 \\
\hline CN palsy & $7(2.8)$ & $1(0.3)$ & $8(1.4)$ & 0.013 \\
\hline latrogenic dissection & $0(0.0)$ & $3(0.9)$ & $3(0.5)$ & 0.121 \\
\hline Groin hematoma & $13(5.2)$ & $7(2.2)$ & $20(3.5)$ & 0.059 \\
\hline Groin infection & $4(1.6)$ & $0(0.0)$ & $4(0.7)$ & 0.025 \\
\hline
\end{tabular}

$\mathrm{CN}=$ cranial nerve; $\mathrm{LOS}=$ length of stay; $\mathrm{POD}=$ postoperative day.

Values are presented as the number of aneurysms (\%) unless stated otherwise.

rate was $4.9 \%$, and the mortality rate was $1.4 \% .{ }^{23}$ Complication rates similar to those in the present series have been reported in some studies of small aneurysms, albeit predominantly in the proximal ICA. Griessenauer and colleagues observed symptomatic complications in $6 \%$ and a modified Rankin Scale score greater than 2 in $4 \%$ of electively treated patients in a study of 117 patients who underwent PED for aneurysms $\leq 7 \mathrm{~mm}$, of which $90 \%$ were located along the ICA. ${ }^{12}$ Chalouhi et al. reported $2 \%$ stroke and $1 \%$ ICH rates in 100 aneurysms smaller than $7 \mathrm{~mm}$ that were treated with PEDs, 92\% of which were located along the ICA. ${ }^{6}$

Major complication rates in this series remained low, despite treatment in locations that were more distal than the locations in other series of small aneurysms. In this series, $19 \%$ of PEDs were deployed in either the ACA or MCA where the risk of stroke is thought to be higher due to the necessity of covering perforating arteries or branches supplying a terminal circulation. Briganti et al. reported on 15 MCA aneurysms treated with PEDs, in which 3 patients $(15 \%)$ experienced ischemic complications resulting in permanent neurological deficit. ${ }^{3}$ IntrePED included 40 MCA aneurysms treated with PEDs and showed an OR of $3.7(\mathrm{p}=0.01)$ for MCA deployment as a predictor of stroke. ${ }^{4}$ Others have reported lower complication rates in small series of distal anterior circulation aneurysms treated with PEDs. In 25 PED treatments for aneurysms beyond the circle of Willis, Martínez-Galdámez et al. observed no permanent morbidity associated with 18 MCA aneurysms but 1 major stroke and 2 TIAs clustered in 4 PED treatments of ACA aneurysms.$^{21}$ Placement of PEDs in the ACA is sufficiently novel that IntrePED included 
TABLE 5. Logistic regression predictors of major complications

\begin{tabular}{|c|c|c|c|c|c|c|c|c|}
\hline \multirow[b]{3}{*}{ Predictor } & \multicolumn{4}{|c|}{ Bivariate } & \multicolumn{4}{|c|}{ Multivariate } \\
\hline & \multirow[b]{2}{*}{ OR } & \multicolumn{2}{|c|}{$95 \% \mathrm{Cl}$} & \multirow[b]{2}{*}{ p Value } & \multirow[b]{2}{*}{ OR } & \multicolumn{2}{|c|}{$95 \% \mathrm{Cl}$} & \multirow[b]{2}{*}{ p Value } \\
\hline & & Lower Bound & Upper Bound & & & Lower Bound & Upper Bound & \\
\hline Age & 1.039 & 1.002 & 1.078 & 0.040 & 1.024 & 0.973 & 1.078 & 0.363 \\
\hline Sex & 0.524 & 0.119 & 2.291 & 0.391 & & & & \\
\hline \multicolumn{9}{|l|}{ Race } \\
\hline \multicolumn{9}{|l|}{ White (ref) } \\
\hline Black & 2.155 & 0.857 & 5.422 & 0.103 & 2.347 & 0.831 & 6.628 & 0.107 \\
\hline Other & 0.593 & 0.074 & 4.757 & 0.623 & 0.680 & 0.077 & 5.973 & 0.728 \\
\hline History of SAH & 2.088 & 0.541 & 5.887 & 0.164 & 1.317 & 0.462 & 3.748 & 0.606 \\
\hline Previously treated & 1.922 & 0.686 & 5.385 & 0.214 & & & & \\
\hline Aneurysm size (mm) & 0.682 & 0.246 & 1.894 & 0.463 & & & & \\
\hline Size (small vs large/giant) & 0.806 & 0.261 & 2.486 & 0.708 & & & & \\
\hline ACA/MCA aneurysm & 2.618 & 0.956 & 7.172 & 0.061 & 3.515 & 1.102 & 11.214 & 0.034 \\
\hline Saccular aneurysm & 0.675 & 0.154 & 2.962 & 0.602 & & & & \\
\hline Classic device & & & & & 3.703 & 1.416 & 9.683 & 0.008 \\
\hline Fluoroscopy time (mins) & 1.019 & 0.883 & 1.175 & 0.799 & & & & \\
\hline Radiation exposure (mGy) & 1.062 & 0.684 & 1.650 & 0.788 & & & & \\
\hline Coiling & 0.731 & 0.094 & 5.670 & 0.764 & & & & \\
\hline \multicolumn{9}{|l|}{ Aortic arch type } \\
\hline \multicolumn{9}{|l|}{$0(\mathrm{ref})^{*}$} \\
\hline 1 & 3.503 & 1.110 & 11.055 & 0.031 & 2.966 & 0.841 & 10.464 & 0.091 \\
\hline 2 & 2.646 & 0.856 & 8.173 & 0.091 & 2.009 & 0.538 & 7.496 & 0.299 \\
\hline 3 & 6.256 & 1.414 & 27.676 & 0.016 & 4.516 & 0.853 & 23.911 & 0.076 \\
\hline Infinity guide sheath & 1.323 & 0.237 & 7.370 & 0.749 & & & & \\
\hline Cat5 distal intracranial catheter & 1.138 & 0.226 & 5.734 & 0.876 & & & & \\
\hline Via27 microcatheter & 0.823 & 0.163 & 4.150 & 0.814 & & & & \\
\hline Cervical ICA tortuosity & 2.460 & 0.966 & 6.270 & 0.059 & 1.653 & 0.649 & 4.201 & 0.291 \\
\hline Type III/IV cavernous ICA & 1.034 & 0.401 & 2.666 & 0.946 & & & & \\
\hline Verapamil infusion & 1.290 & 0.300 & 5.552 & 0.732 & & & & \\
\hline Balloon angioplasty & 2.689 & 0.945 & 7.651 & 0.064 & 2.686 & 0.748 & 9.648 & 0.130 \\
\hline Pipeline removal/cork & 0.860 & 0.170 & 4.358 & 0.856 & & & & \\
\hline In situ thrombosis & 4.175 & 1.774 & 9.824 & 0.001 & 4.307 & 1.527 & 12.149 & 0.006 \\
\hline
\end{tabular}

* Unavailable for review.

just 10 cases; however, we have had high occlusion rates and low complication rates using PED to treat uncoilable anterior communicating artery-region aneurysms.? Given the anatomical challenges, it was not surprising that these more distal anterior circulation deployments were a predictor of major complications in this study, although the presence of more such treatments did not undermine the overall excellent results.

There was a significant reduction in the major complication rate from $5.6 \%$ to $1.9 \%$ with the transition from the Pipeline classic to the Flex in February 2015. While possible alternative explanations exist and will be addressed, we attribute this improvement primarily to the ease of using the newer generation device. As detailed elsewhere, ${ }^{19}$ the implant with PED Flex is the same as PED classic, but the delivery system was completely redesigned. The first modification is that the proximal end of the PED Flex was mounted on a pad that allows resheathing when up to $90 \%$ of the device is deployed. The authors of an early experience with Flex noted the use of resheathing for 18 of 39 devices (46\%) to promote distal opening, to improve apposition, or to reposition the device with no associated dissection, perforation, or thromboembolic events. ${ }^{20}$ The second modification is that a stiffer stainless steel pusher wire was introduced to navigate tortuosity and facilitate retracking of the microcatheter. As noted in our initial report on 44 PED Flex cases, this facilitates bumping the device with the microcatheter or intermediate catheter to improve apposition and preserves access in situations in which additional devices or manipulation is needed.7 The third modification, at the distal end of the delivery system, was the abandonment of the capture coil in favor of Teflon sleeves and the addition of an angled-tip coil. This eliminates the need for torque to release the device and softens 
the tip of the delivery system to reduce the risk of dissection or perforation, although some have found it difficult to recapture.22

These delivery system improvements have led to shorter procedure times, but previous series were underpowered to show improved safety. Le and colleagues compared 58 PED classic procedures with 38 Flex procedures and saw statistically significant reductions in fluoroscopy time, radiation exposure, and device deployment failure associated with Flex, all of which were also observed in the present study. ${ }^{16}$ In that series, the rate of permanent neurological morbidity was $3.4 \%$ in the classic group and $0 \%$ in the Flex group, but this difference was not significant. The limited number of major complications described in other reports of Flex appears to be related to the stent or clinical scenario rather than the delivery system. Two symptomatic anterior choroidal artery strokes in the first 30 Flex cases (6.6\%) performed by Martínez-Galdámez and colleagues both occurred in large aneurysms treated with overlapping devices, which are known to be associated with higher risk..$^{20}$ The one major complication in our initial 44 cases $(2.3 \%)$ was a stroke secondary to device thrombosis in a patient who was noncompliant with prescribed antiplatelet agents. ${ }^{8}$ The current study includes 568 total procedures (252 classic and 316 Flex), and on multivariate logistic regression, Pipeline device generation (in addition to intraprocedural stent thrombosis) was one of the 2 most significant predictors of major complication.

There are possible alternative explanations for the difference in complication rates that were observed in this study-including an evolving patient population, improving catheter technology, and the user experience curve-all of which, we believe, are secondary to the delivery system improvements with Pipeline Flex. First, our practice has evolved over time, and the patient population and type of aneurysm treated have changed in subtle but significant ways. Patients treated with Flex were more likely to have recurrent aneurysms or aneurysms along the ACA or MCA, adding complexity to these cases. Patients treated with Flex were also younger, had smaller aneurysms, and had less cervical tortuosity, all potentially reducing the complexity of these cases. We performed a multivariate logistic regression accounting for these differences, and the device type remained the strongest predictor of major complications.

A second alternative explanation is that just as the Pipeline device has been updated, catheter technology has evolved and improved during the 5 years we have been using Pipeline. Our traditional triaxial setup, including the Flexor Shuttle or Neuron MAX guide sheath, Navien distal intracranial catheter, and Marksman microcatheter, was used for more than 95\% of Pipeline classic cases. Alternatively, the Cat5 distal intracranial catheter was used for $48 \%$ of Flex procedures for its improved trackability and stability. ${ }^{10}$ We have also come to favor the Via27 microcatheter for its resheathing ability and pushability and have used it for 56\% of Flex cases. ${ }^{17}$ These enhancements appear incremental, and no catheter was a significant predictor of complications on bivariate or multivariate analysis.

A third alternative explanation for the observed differences in complication rates between Flex and classic devices is the existence of a learning curve, both in terms of technical skill and case selection, that favored the newer device. Jabbour and colleagues sought to demonstrate this learning curve in their 109 patients treated with PEDs in whom they observed a complication rate of $16.2 \%$ in the first third and $5.6 \%$ in the final third. ${ }^{13}$ There were other differences between the groups, however, including a reduction in the number of devices used for each procedure, and "experience" was not a significant predictor of complications on multivariate analysis. In a prospective, consecutive series of 100 patients, Burrows and colleagues failed to see a reduction in complications over time as they surmounted the learning curve..$^{5}$ They theorized that this might be due to increased off-label treatments but provided limited information about the patients and aneurysms treated. In that series, periprocedural technical events, such as device migration or incomplete expansion, and transient clinical events, such as stent thrombosis or worsening cranial nerve palsy, were observed in a constant one-third of patients over time. ${ }^{5}$ Attempting to account for the learning curve, we repeated the multivariate analysis for predictors of major complications while excluding the first 20 procedures with each device type for each attending neurosurgeon, and Pipeline classic remained a significant predictor and the strongest predictor of major complications.

Increased awareness of variability in the response to Plavix has led many interventionists to manipulate antiplatelet medications to achieve a goal P2Y12 level, which some have ventured explains lower complication rates in recent PED series. ${ }^{11}$ Our approach to antiplatelet therapy, however, did not change over the course of this study. Hyperresponse could lead to procedural rescheduling but has always been primarily assessed clinically. We take no action for a hyporesponse to Plavix (PRU > 200) and have seen excellent outcomes in this population. ${ }^{2}$

The retrospective, nonrandomized nature of this study is its main limitation and drives these differences in patient population, catheter technology, and operator experience. In addition, there is variability within the Pipeline literature in how major complications are defined. For instance, the primary end point of PUFS was major ipsilateral stroke or neurological death, which excluded some instances of hemorrhage, stroke, and fistula development that were not associated with a decline in the modified Rankin Scale score. ${ }^{1}$ IntrePED, on the other hand, distinguished between major and minor complications by the persistence of symptoms beyond 7 days. ${ }^{15}$ We adhere more closely to the latter definition. While this may muddy external comparisons, it does not affect internal validity or alter the conclusion that Flex is associated with fewer complications than Pipeline classic.

\section{Conclusions}

The type of anterior circulation aneurysms being treated with flow diversion has evolved over time from primarily large proximal carotid artery aneurysms to small carotid artery aneurysms to more distal anterior circulation aneurysms. This study demonstrates that flow diversion can be performed safely for a wide variety of anterior circulation aneurysms with a low rate of major complications. The introduction of Pipeline Flex was associated with a reduc- 
tion in the risk of major complications, which persists on multivariate analysis.

\section{References}

1. Becske T, Kallmes DF, Saatci I, McDougall CG, Szikora I, Lanzino G, et al: Pipeline for uncoilable or failed aneurysms: results from a multicenter clinical trial. Radiology 267:858868,2013

2. Bender MT, Lin LM, Colby GP, Lubelski D, Huang J, Tamargo RJ, et al: P2Y12 hyporesponse (PRU>200) is not associated with increased thromboembolic complications in anterior circulation Pipeline. J Neurointerv Surg 9:978-981, 2017

3. Briganti F, Delehaye L, Leone G, Sicignano C, Buono G, Marseglia M, et al: Flow diverter device for the treatment of small middle cerebral artery aneurysms. J Neurointerv Surg 8:287-294, 2016

4. Brinjikji W, Lanzino G, Cloft HJ, Siddiqui AH, Boccardi E, Cekirge S, et al: Risk factors for ischemic complications following Pipeline Embolization Device treatment of intracranial aneurysms: results from the IntrePED study. AJNR Am J Neuroradiol 37:1673-1678, 2016

5. Burrows AM, Cloft H, Kallmes DF, Lanzino G: Periprocedural and mid-term technical and clinical events after flow diversion for intracranial aneurysms. J Neurointerv Surg 7:646-651, 2015

6. Chalouhi N, Zanaty M, Whiting A, Yang S, Tjoumakaris S, Hasan D, et al: Safety and efficacy of the Pipeline Embolization Device in 100 small intracranial aneurysms. J Neurosurg 122:1498-1502, 2015

7. Colby GP, Bender MT, Lin LM, Beaty N, Huang J, Tamargo RJ, et al: Endovascular flow diversion for treatment of anterior communicating artery region cerebral aneurysms: a single-center cohort of 50 cases. J Neurointerv Surg 9:679685, 2017

8. Colby GP, Lin LM, Caplan JM, Jiang B, Huang J, Tamargo $\mathrm{RJ}$, et al: Immediate procedural outcomes in 44 consecutive Pipeline Flex cases: the first North American single-center series. J Neurointerv Surg 8:702-709, 2016

9. Colby GP, Lin LM, Gomez JF, Paul AR, Huang J, Tamargo $\mathrm{RJ}$, et al: Immediate procedural outcomes in 35 consecutive pipeline embolization cases: a single-center, single-user experience. J Neurointerv Surg 5:237-246, 2013

10. Colby GP, Lin LM, Xu R, Beaty N, Bender MT, Jiang B, et al: Utilization of a novel, multi-durometer intracranial distal access catheter: nuances and experience in 110 consecutive cases of aneurysm flow diversion. Interv Neurol 6:90-104, 2017

11. Delgado Almandoz JE, Crandall BM, Scholz JM, Fease JL, Anderson RE, Kadkhodayan Y, et al: Last-recorded P2Y12 reaction units value is strongly associated with thromboembolic and hemorrhagic complications occurring up to 6 months after treatment in patients with cerebral aneurysms treated with the pipeline embolization device. AJNR Am J Neuroradiol 35:128-135, 2014

12. Griessenauer CJ, Ogilvy CS, Foreman PM, Chua MH, Harrigan MR, He L, et al: Pipeline Embolization Device for small intracranial aneurysms: evaluation of safety and efficacy in a multicenter cohort. Neurosurgery 80:579-587, 2017

13. Jabbour P, Chalouhi N, Tjoumakaris S, Gonzalez LF, Dumont AS, Randazzo C, et al: The Pipeline Embolization Device: learning curve and predictors of complications and aneurysm obliteration. Neurosurgery 73:113-120, 2013

14. Kallmes DF, Brinjikji W, Boccardi E, Ciceri E, Diaz O, Tawk R, et al: Aneurysm Study of Pipeline in an Observational Registry (ASPIRe). Interv Neurol 5:89-99, 2016

15. Kallmes DF, Hanel R, Lopes D, Boccardi E, Bonafé A, Cekirge $S$, et al: International retrospective study of the pipeline embolization device: a multicenter aneurysm treatment study. AJNR Am J Neuroradiol 36:108-115, 2015
16. Le EJ, Miller T, Serulle Y, Shivashankar R, Jindal G, Gandhi D: Use of Pipeline Flex is associated with reduced fluoroscopy time, procedure time, and technical failure compared with the first-generation Pipeline embolization device. J Neurointerv Surg 9:188-191, 2016

17. Lin LM, Colby GP, Bender MT, Xu R, Huang J, Tamargo RJ, et al: Use of the 0.027-inch VIA microcatheter for delivery of Pipeline Flex: a technical note. J Neurointerv Surg 9:689693, 2017

18. Lin LM, Colby GP, Kim JE, Huang J, Tamargo RJ, Coon AL: Immediate and follow-up results for 44 consecutive cases of small $(<10 \mathrm{~mm})$ internal carotid artery aneurysms treated with the pipeline embolization device. Surg Neurol Int 4:114-123, 2013

19. Martínez-Galdámez M, Gil A, Caniego JL, Gonzalez E, Bárcena E, Pérez S, et al: Preliminary experience with the Pipeline Flex Embolization Device: technical note. J Neurointerv Surg 7:748-751, 2015

20. Martínez-Galdámez M, Pérez S, Vega A, Ruiz P, Caniego JL, Bárcena E, et al: Endovascular treatment of intracranial aneurysms using the Pipeline Flex embolization device: a case series of 30 consecutive patients. J Neurointerv Surg 8:396-401, 2016

21. Martínez-Galdámez M, Romance A, Vega P, Vega A, Caniego JL, Paul L, et al: Pipeline endovascular device for the treatment of intracranial aneurysms at the level of the circle of Willis and beyond: multicenter experience. J Neurointerv Surg 7:816-823, 2015

22. Mooney MA, Moon K, Gross BA, Ducruet AF, Albuquerque FC: Incidence of delivery wire recapture failure with the Pipeline Flex device. J Neurointerv Surg 9:571-573, 2017

23. Yu SC, Kwok CK, Cheng PW, Chan KY, Lau SS, Lui WM, et al: Intracranial aneurysms: midterm outcome of pipeline embolization device - a prospective study in 143 patients with 178 aneurysms. Radiology 265:893-901, 2012

\section{Disclosures}

Dr. Colby: consultant for MicroVention; and research support from and participant in clinical trials for Medtronic and Stryker. Dr. Lin: consultant for Medtronic Neurovascular; and receives research support from MicroVention and Stryker. Dr. Huang: ownership in Longeviti. Dr. Coon: consultant and proctor for Stryker Neurovascular, Medtronic, and MicroVention.

\section{Author Contributions}

Conception and design: Coon, Colby, Bender, Huang, Tamargo. Acquisition of data: Coon, Colby, Bender, Jiang, Westbroek, Varjavand, Campos. Analysis and interpretation of data: Coon, Colby, Bender, Lin, Beaty, Caplan, Jiang, Westbroek, Varjavand, Campos. Drafting the article: Coon, Colby, Bender, Lin, Beaty, Caplan, Jiang, Westbroek, Campos, Huang, Tamargo. Critically revising the article: Coon, Colby, Bender, Lin, Beaty, Caplan, Jiang, Westbroek, Campos, Huang, Tamargo. Reviewed submitted version of manuscript: all authors. Approved the final version of the manuscript on behalf of all authors: Coon. Statistical analysis: Colby, Bender, Varjavand. Study supervision: Tamargo.

\section{Supplemental Information \\ Previous Presentations}

Portions of this study were presented as an oral presentation at the 2017 AANS Annual Scientific Meeting, Los Angeles, CA, April 22-26, 2017.

\section{Correspondence}

Alexander Coon: Johns Hopkins Medicine, Baltimore, MD. acoon2@jhmi.edu. 